\title{
Perspectivas de adolescentes sobre gênero, relacionamentos e violências
}

Isadora Oliveira Rocha E-mail:

isadora.oliveirarocha@gmail.com Universidade de Brasília, Brasília, Distrito Federal, Brasil

Glaucia Ribeiro Starling Diniz E-mail: gglaucia_1397@gmail.com Universidade de Brasília, Brasília, Distrito Federal, Brasil

\section{RESUMO}

\begin{abstract}
O objetivo deste artigo é analisar de que maneiras adolescentes que presenciam suas mães como vítimas da violência doméstica por aqueles que representam a figura paterna, compreendem os papéis de gênero, relacionamentos e violências em seu cotidiano. Para atingir este objetivo o presente estudo foi construído, ao buscar acessar tais compreensões no processo de adolescer, a partir da exposição aos relacionamentos violentos que compõem a dinâmica conjugal dos pais das adolescentes. Trata-se de um recorte de uma dissertação de mestrado, elaborada através das teorias feministas, realizada com duas adolescentes do gênero feminino. Constatou-se que as experiências de violência transpassam o (complexo) funcionamento das relações familiares. As adolescentes constroem suas ideias e conceitos de "ser mulher" e "ser homem" na contemporaneidade, assim como conceitos de relacionamentos amorosos e violência, a partir relações conjugais parentais próximas às suas convivências.
\end{abstract}

PALAVRAS-CHAVE: Violência doméstica. Adolescentes. Mães. Gênero. 


\section{INTRODUÇÃO}

A palavra "violência" tem vários significados. "Violência" é oriunda do verbo latino violare, o mesmo que transgredir, profanar. Ao seguir a tradição clássica greco-romana, violência seria o desvio "do curso natural das coisas" (ADORNO, 2011, p. 556). Segundo este mesmo autor, na contemporaneidade, por "violência" compreendem-se ações humanas opostas, que questionam e/ou perturbam a ordem social ou a paz reconhecidas perante a lei.

No Brasil há a tendência de situações violentas não serem consideradas como tal. A violência em nossa sociedade não é percebida como estrutural, e sim, "como um fato esporádico de superfície" (CHAUI, 2011, p. 349). A violência passa a ser vista apenas longe de nós e, por consequência, ignorada através de nossos olhares. Esta violência organiza e estrutura relações sociais. Ao rejeitarmos a quantidade de violências que perpassam o nosso dia-a-dia, reforçamos o processo de naturalização desta (CHAUI, 2011).

Ao usarmos o termo "violências" no plural, a intenção é deixar evidente que existem múltiplas formas de manifestação das violências. Há violência verbal, física, emocional, social, racial, política, de gênero. Uma variedade de grupos e de pessoas são vítimas deste(s) fenômeno(s), portanto (CHAUI, 2011).

A violência de gênero aparece como um tipo de violência que atravessa a vivência de mulheres de todas as idades e grupos sociais. Estas violências ocorrem de modo singular e específico (BANDEIRA, 2014).

A violência contra a mulher tem múltiplos autores do sexo masculino. Lourdes Maria Bandeira Bandeira e Ana Liése Thurler (2010) apontam que este tipo de violência pode ser cometido pelo marido ou companheiro da mulher, bem como pelo pai, irmão, cunhado, tio, avô, sem excluir também a pessoa que exerce a função de pai (padrasto).

Sabrina Mazo D'Affonseca e Lúcia Cavalcanti de Albuquerque Williams (2011) apontam a violência doméstica contra as mulheres como um problema mundial, de ordem social e de saúde pública, cujas vítimas independem de raça, etnia, classe social, religião, nacionalidade, grau de escolaridade e/ou idade. Esta violência tem como uma característica preocupante a brutalidade na qual os crimes vêm sendo cometidos, fator que gera graves sequelas às vítimas (SILVA et al 2007; WAISELFISZ, 2015). Um desafio que torna a violência doméstica um problema ainda maior, é o fato de que os episódios de violência são, na maioria das vezes, realizados na presença de crianças e adolescentes (EVANS et al, 2008).

A violência perpetrada contra a mulher, especialmente quando esta mulher já é mãe, afeta e prejudica "o bem-estar, a integridade física, psicológica, a liberdade e o direito ao pleno desenvolvimento de qualquer membro da família, especialmente as crianças" (BANDEIRA; THURLER, 2010, p. 164). Neste cenário, um novo tipo de violência pode ser desenvolvido: a violência intrafamiliar (BRASIL, 2001; SANTOS; MORÉ, 2011).

A convivência em um núcleo familiar perpassado por violência(s) apresenta influência na construção pessoal de adolescentes do gênero feminino acerca de ideias de "gênero", "violência" e "relacionamento"? Sabemos que a construção da identidade e as necessidades de adolescentes são construídas a partir dos meios em que elas/es vivem: psicológico, econômico, social, cultural e familiar (RESSEL et al 2009).

O questionamento supracitado motiva a realização da presente pesquisa. A semiestruturadas com adolescentes do sexo feminino, é pretendido entender se o 
fato de viverem em núcleos familiares perpassados por violências domésticas, as adolescentes têm seus conceitos de relacionamento, gênero e violência doméstica, influenciados por tais vivências. Contou-se com filhas das participantes do Projeto Extensão e Ação Contínua "Maria da Penha - Ação e Proteção", para a realização da pesquisa.

\section{METODOLOGIA}

Trata-se de uma pesquisa feminista, construída a partir do diálogo com teorias de gênero. É importante localizar o estudo a partir das teorias feministas, porque se assume a relevância de elementos sociais e políticos no processo de construção individual e social das participantes da pesquisa (ACKERLY; TRUE, 2010).

As participantes da pesquisa são adolescentes que presenciaram as mães em alguma situação de violência doméstica, cujo autor da violência realizava a função paterna das adolescentes. As participantes foram localizadas a partir do Projeto de Extensão e Ação Contínua "Maria da Penha - Ação e Proteção". É um projeto interdisciplinar, realizado há nove anos no Núcleo de Práticas Jurídicas da Universidade de Brasília (NPJ/UnB). O intuito do projeto é oferecer acompanhamento psicológico e jurídico gratuito às mulheres de condição socioeconômica vulnerável, vítimas de violências na conjugalidade.

Foram identificadas quatro famílias que se adequavam aos critérios de inclusão para participação da pesquisa. Os critérios de inclusão utilizados foram os seguintes: 1) mulheres vítimas de violência doméstica; 2) mulheres que têm filhas adolescentes; 3) participantes ativas do "Projeto de Extensão e Ação Contínua "Maria da Penha - Ação e Proteção".

O movimento de relembrar e, de certa forma, reviver situações de violência causa dor, de acordo com Gláucia Ribeiro Starling Diniz e Miriam Cássia Mendonça Pondaag (2004). Falar sobre as violências sofridas representa dificuldade para mulheres, porque envolve a verbalização de marcas psicológicas oriundas de traumas, ainda não completamente superados. É possível associar tal fato, ao número de participantes da pesquisa: apenas duas mulheres (e suas filhas) consentiram com a participação nesta.

A proposta da pesquisa foi apresentada em um mesmo momento às mães e suas filhas. Por se tratar de uma pesquisa com adolescentes, faz-se importante o envolvimento de responsáveis no processo, assim como para apresentação ao Termo de Assentimento. Todas as questões foram elucidadas através da leitura em conjunto do Termo de Assentimento e o Termo de Consentimento Livre e Esclarecido para as jovens participantes e suas mães.

A pesquisa teve aprovação do comitê de ética da Instituição de Ensino Superior (CAAE: 65312716.0.0000.5540). Todos os nomes que serão aqui apresentados são fictícios.

A coleta dos dados se deu através da realização de uma entrevista semiestruturada com cada uma das participantes, de maneira individual. A entrevista objetivava compreender como as adolescentes percebiam os relacionamentos violentos que suas mães foram expostas e se as adolescentes sofreram com algum impacto por presenciar tais violências.

As entrevistas foram transcritas e, a partir do processo de categorização de Laurence Bardin (2009), foi possível estabelecer três categorias: 1) As adolescentes enquanto vítimas diretas da violência; 2) História de vida/História de violências; 3 ) Perspectivas das adolescentes sobre gênero, relacionamento e violência. Por ser 
um recorte de uma dissertação de mestrado, no presente artigo apresentaremos os resultados referentes à categoria: Perspectivas das adolescentes sobre gênero, relacionamento e violência doméstica.

\section{RESULTADOS E DISCUSSÕES}

Torna-se difícil a separação entre a vida das adolescentes e o núcleo familiar violento. É notável que as percepções das adolescentes sobre os diferentes assuntos ("gênero", "relacionamento" e "violência"), tornam-se associadas às vivências de violências às quais elas foram expostas.

A partir dos relatos das adolescentes é notável a semelhança de discursos. Fato este que nos motivou a construir um paralelo entre suas percepções de vida. A apresentação dos dados será realizada a partir de três categorias, através das temáticas "gênero", "relacionamentos amorosos" e "violência doméstica". A temática "gênero" é trabalhada no presente artigo a partir dos subtítulos "O papel social esperado da mulher" e "O papel social esperado do homem", a partir de expectativas histórico-culturais que envolvem tais papéis. "Relacionamentos amorosos" e "Violência doméstica" são englobados em um mesmo subtítulo e apresentação, a partir da percepção das autoras de que ambos estão relacionados nas falas das participantes.

\section{O papel social esperado da mulher}

Larissa é uma adolescente de catorze (14) anos. É nordestina e mudou recentemente do Piauí para Brasília. Atualmente é residente na casa de uma vizinha, devido aos conflitos violentos entre sua mãe, Andreia, e o padrasto, Roberto.

O motivo que ocasionou na mudança de Larissa para Brasília foi para "ajudar" a mãe, Andreia. Larissa mudou-se com o irmão mais velho, contudo, o irmão, devido às violências que a mãe sofria, preferiu retornar a cidade de origem. Larissa afirma saber "da culpa da minha mãe, por ter deixado eu e meu irmão lá. Aí eu vim pra cá, ele voltou, mas eu fiquei". A história de Larissa começa a se envolver com a vivência de violências da mãe, quando decide se (re) aproximar desta.

Nesse contexto cabe perguntar: "Que culpa é esta que a mãe sente por ter se mudado para longe dos filhos?". A culpa é construída em função do papel designado à mulher de cuidar. A mulher deve ser a responsável pela manutenção e cuidado do ambiente doméstico, das/os filhas/os e do marido (DINIZ; FÉRESCARNEIRO, 2012; NARVAZ; KOLLER, 2006). A dinâmica do cuidado a ser realizado pela figura feminina é perigosa. Há a repetição do padrão do "cuidado" na filha de Andreia, Larissa - porém, desta vez, de filha para mãe.

A função feminina vinculada ao cuidado é histórica e culturalmente reforçada através do patriarcado. É comum que a mulher seja culpabilizada por "escolher" não exercer uma função que é culturalmente designada e que deve ser assumida por ela (CARLOTO; MARIANO, 2008).

Em relação ao relacionamento da mãe e do padrasto Roberto, Larissa aponta que este "não tá nem aí pra minha mãe, só que quando ela tá fora de casa ele liga e fala pra voltar". É evidente a presença do sentimento e do comportamento de posse e controle neste relacionamento. 
Andreia exerce todas as funções que "devem" ser realizadas por uma mulher, segundo Larissa. A adolescente, mais de uma vez, informou que sua mãe é esposa, mãe e que exerce inclusive o papel materno em relação ao filho do companheiro.

Larissa descreve a mãe como "cuidadora", "amiga", "boa mãe", "fiel", entre outras características que também são citadas por Bandeira (2014). Dentre todas as funções que Andreia desempenha no seu cotidiano, estas não são suficientes para privá-la da violência realizada por Roberto. As funções e os sentidos que caracterizam as vidas das mulheres, muitas vezes não são suficientes para inibirem os homens de perpetrarem a violência, através da dominação e do poder sobre os corpos e as vidas das mulheres (Bandeira, 2014).

Amanda, a segunda participante e adolescente da pesquisa, vivencia situações semelhantes ao relato de Larissa. Amanda tem doze (12) anos, mora com sua mãe e irmã mais nova. O relacionamento conjugal entre os pais de Amanda também era perpassado por violências constantes contra a mãe de Amanda, Márcia.

Os motivos das brigas que aconteciam entre seus pais são definidos pela adolescente como:

meu pai queria só mandar na minha mãe, minha mãe não podia nem fazer nada. Se fizesse, mesmo se fizesse certo, ele brigava. Ela não podia sair na rua, não podia conversar com ninguém, era o dia inteiro em pé fazendo tudo".

Amanda informa que a mãe

não parava nem sequer um momento para sentar no sofá (...) ficava andando de um lado pro outro, mesmo se não tivesse o que fazer ela estava andando para arrumar.

Em situação semelhante à relatada por Larissa, a mãe de Amanda também sofreu violências motivadas pela imposição do papel que uma mulher deve desempenhar em casa. As violências perpetradas como modo de punição, sofridas por Márcia, não eram apenas físicas. Amanda indica que seu pai "gritava muito" com sua mãe quando "meu pai queria mandar na minha mãe e ela não queria". 0 pai ficava "sempre na rua" e "voltava só de noite", enquanto a mãe organizava a casa e cuidava das filhas.

Fica evidente novamente que as prescrições do modelo patriarcal aparecem como um dos principais traços culturais, capazes de justificar as violências contra as mulheres. Existem outros elementos determinantes na dinâmica da violência doméstica, ou seja, "o patriarcado e a dominação masculina, se tomados isoladamente, seriam causas insuficientes para se explicar a violência contra a mulher" (Bandeira, 2014, p. 457).

O fato é que estas ideias e conceitos simbolizam processos de dominação e são carregados de desdobramentos que não podem ser ignorados ao estudarmos os ambientes familiares (BANDEIRA, 2014). Tais elementos nos auxiliam na compreensão da complexa relação entre violência doméstica e a saúde mental das/os envolvidas/os em lares transpassados por esta(s) violência(s).

"Ser mulher" é equivalente a um lugar que limita a importância e ação desta mulher. As mulheres são tratadas como se não possuíssem desejos, ambições ou 
aspirações próprias (PEIXOTO, 2016). Cabe pontuar a função do gênero feminino voltada para além do cuidado, mas também, para a disponibilidade em servir.

Como passam a ser construídas as subjetividades destas adolescentes neste cenário de violência intrafamiliar? Quais ideais as adolescentes passam a construir a partir da função da mulher na sociedade e/ou em um relacionamento conjugal? A dinâmica da violência doméstica é um fator determinante que precisa ser observado.

A partir da fala das adolescentes é notável a queixa e a percepção destas em estranhar o comportamento daqueles que realizam a função paterna, em relação ao comportamento e função de suas mães. Ambas as adolescentes compreendem as mães enquanto seres que não possuem autonomia, mas sim "um ser para outros" (DINIZ; PONDAAG, 2004, p. 174).

\section{O papel social esperado do homem}

A cultura patriarcal determina uma hierarquia de poderes dentro e fora dos lares, como Heleieth Saffioti (2015) destaca. Cléber, pai de Amanda, tinha no diaa-dia familiar a autonomia de "sair de casa" quando quisesse segundo a adolescente. A mãe de Amanda, por outro lado, precisava manter tudo em ordem na casa e com as filhas, a todo instante.

Na família de Larissa, o padrasto viaja, trabalha fora e se envolve sexualmente com outras pessoas, sem o consentimento da esposa, enquanto ela não pode fazer o mesmo, de acordo a adolescente Larissa. Há, inclusive, "explosões de ciúme" por parte do padrasto de Larissa, que resultam em episódios de violência. A adolescente afirma que o comportamento do padrasto é motivado pelo fato deste acreditar que, quando a mãe da adolescente sai de casa, ela o está traindo.

Nos exemplos dados pelas adolescentes, percebemos o poder masculino na construção de regras para o funcionamento daquelas famílias. O poder é relacionado aos homens e a obediência deve ser exercida pelas mulheres. À mulher é direcionada a função de manter a lógica familista do pai-padrasto (BANDEIRA, 2014).

Durante a entrevista, quando Larissa relatava sobre as traições de seu padrasto, afirmou não entender por que essa situação acontece. Segundo a adolescente

eu paro pra pensar e fico... minha mãe não 'trai ele' com ninguém, não 'pega' ninguém, faz de tudo em casa, aguenta os desaforos do filho dele e eu não dou trabalho nenhum pra ele (...) me pergunto o que minha mãe fez pra ele.

De acordo com Larissa:

(...) homem tem que trair, tem uns que não trai, mas tem uns que trai. Então eu só vou me juntar com um homem quando eu tiver certeza que ele vai ser fiel, vai me compreender. Vai ser... não vai mentir pra mim. Quando eu tiver certeza disso, aí sim, ai vou me juntar.

O adultério masculino é uma prática social comum em nossa sociedade e é frequentemente vista como natural (BERNADINO; SILVA, 2017). É reforçado no comportamento do homem que o ato sexual praticado constantemente é historicamente reconhecido como "um fator de honra à virilidade" (BERNADINO; SILVA, 2017, p. 150). 
Saffioti (2015, p. 28) afirma que "o homem foi educado para ir à caça", no sentido sexual da expressão. Além da "caça", o homem também é educado para não se envolver emocionalmente. "Homem", para Larissa, "é bem diferente da mulher porque ele não sabe, tem alguns que não compreende, mas têm alguns que não, ele não tem paciência, eles não têm capacidade de entender a mulher como a mulher entende o homem".

Diniz (2011, p. 17) ressalta que "a divisão sexual do trabalho fez com que as mulheres fossem colocadas na posição de responsáveis pelo processo emocional da relação". Ao mesmo tempo, são naturalizadas as ações masculinas, entendendo o seu funcionamento emocional e/ou comportamental, enquanto algo dado, pronto e não enquanto construção social, aprendida a partir das relações.

À mulher é destinado o papel de paciência, compreensão e passividade. 0 comportamento omisso do homem é popular e constantemente justificado. É preciso considerar o contexto sociocultural que reforça estes estereótipos. Os homens "foram ensinados a valorizar a racionalidade e a esconder (ou mesmo negar) tudo que esteja relacionado à emotividade" (DINIZ, 2011, p. 17).

\section{Relacionamentos amorosos e violência doméstica}

Ao definir "violência", Larissa afirmou: "É uma coisa que não é boa". A adolescente complementa:

(...) porque qualquer mulher é pra ser tratada com carinho, amor, compreensão, ser valorizada, não ser maltratada, não ser chamada de vagabunda, mentirosa.

Amanda indica:

Realmente é uma coisa que não deveria acontecer, porque realmente a lei não ta adiantando muito. Porque as mulheres, mesmo sendo mulher ou homem sofrendo essa violência, tinha que criar coragem e ir na delegacia.

Ambas as adolescentes relacionaram a "violência" com a existência das violências contra as mulheres, ou seja, as violências sofridas por suas mães, às quais elas presenciaram.

"Relacionamento violento" é definido por Larissa como: "isso é uma coisa de caso de polícia". Amanda pontua diferenças entre relacionamentos com a presença e ausência de violências e faz comparação:

Realmente dá pra ver a diferença entre um relacionamento amoroso e violento, como eu vi no relacionamento do namorado da minha mãe e meu pai. Quando era com meu pai, vivia brigando. Com o namorado, os dois juntos sem nem sequer briga.

Ambas as adolescentes demonstram receio em se envolver em relacionamentos e eles se transformarem em violentos, no futuro. Amanda afirma:

às vezes tenho medo, se acontecesse eu ia falar com minha mãe.

Larissa indica: 
As repercussões da exposição à violência doméstica na vida de adolescentes apontam para a transgeracionalidade da violência (EVANS et al, 2008; SANTOS; MORÉ, 2011; RESSEL et al, 2009). Essas pesquisas ressaltam a tendência de crianças/adolescentes repetirem comportamentos de violência em relacionamentos futuros, seja na posição de perpetradores ou de vítimas.

Nossa pesquisa não é longitudinal. O que podemos apontar, neste momento, é o fato de as adolescentes participantes da pesquisa demonstrarem resistência quanto a se envolverem romanticamente com outras pessoas. O receio pode ser justificado, pela presença das violências que transpassaram o cotidiano familiar das adolescentes.

O fato é que elas perceberam que as pessoas que desempenham a função parental, de cuidado, em suas vidas estão relacionadas aos comportamentos violentos enquanto violentadores ou violentadas - e elas optam pelo não desejo em (re)vivenciar tais agressões. É importante ressaltar a referência que pais e mães representam às vidas de seus filhos. São verdadeiros modelos de comportamento e afetividade, atuantes enquanto influenciadores no processo construtivo das próprias ações e emoções das/os filhas/os (JORDÃO, 2008; SANTOS; MORÉ, 2001).

Homens e mulheres aprendem, desde muito cedo, papéis socialmente aceitos e esperados para cada um/a (DINIZ, 2011). Papéis estes, inclusive relacionados à como se comportar nos relacionamentos interpessoais, de acordo com a inserção no sistema sexo-gênero. As adolescentes, nas entrevistas, afirmam que não querem ter filhos ou casar. Ao fazer tal afirmação, rompem com as normas e prescrições de família tradicional a que suas mães e tantas outras mulheres são e foram submetidas.

Entendemos que nós, seres humanos, somos pessoas em constante construção (DINIZ, 2011). É notável que a postura das adolescentes acerca do casamento e do ter filhos, possa e deva sofrer modificações. Ainda assim, é importante destacar o fato de que a exposição ao relacionamento agressivo no ambiente familiar, fez com que as adolescentes, nos dias atuais, utilizando sempre da lembrança das violências sofridas por suas mães, decidissem que aquele não é um lugar que elas desejam ocupar no futuro, especialmente se for composto pelas mesmas características de suas próprias casas.

As demais reflexões realizadas pelas adolescentes no decorrer das entrevistas, demonstram que as lembranças de distintas violências sofridas pelas mães, são constantes nas falas das participantes. Ao discorrer sobre o papel esperado da mulher e do homem na sociedade atual, as adolescentes também utilizam de episódios familiares para verbalizarem suas inquietações.

É fato que as adolescentes, neste complexo processo de violência doméstica o qual suas mães foram submetidas, estão envolvidas diretamente na dinâmica violenta. A violência doméstica é um fenômeno que se estende às/os filhas/os de mulheres agredidas (ANGELIM; DINIZ, 2003; BANDEIRA; THURLER, 2010). Por ainda ser um fenômeno de estudo, intervenção e questionamento, recente (BANDEIRA, 2014), existem escassas pesquisas acerca da exposição de outros membros familiares a tais violências, principalmente a partir de uma perspectiva longitudinal. Ressaltamos a importância, portanto, de novos olhares científicos serem aplicados à temática aqui proposta. 


\section{CONSIDERAÇÕES FINAIS}

A violência doméstica é um fenômeno que se estende às/os filhas/os de mulheres agredidas. Dado este que foi comprovado na atual pesquisa, a partir dos relatos das adolescentes. As participantes com frequência associam fatos do cotidiano à dinâmica familiar (violenta) que um dia foi vivenciada por elas.

Compreendemos a adolescência como um período único para cada adolescente que a vive (JORDÃO, 2008). Consideramos, portanto, que ao falar de adolescência, precisamos englobar aspectos socioeconômicos, étnicos, raciais, a inserção no sistema sexo-gênero, nacionalidade, orientação sexual, religião, entre tantos outros fatores. Devemos também considerar os espaços relacionais e sua influência na construção subjetiva de adolescentes. É inegável que o núcleo familiar deve ter destaque neste cenário.

Elucidamos que um ambiente familiar no qual a mãe é vítima de violência doméstica e as violências são extensivas aos filhos, trata-se de um cenário de violência intrafamiliar. A violência intrafamiliar vivida a partir desta perspectiva, ainda não apresenta destaque e/ou reconhecimento em relação à sua gravidade de um modo geral. A escassez de pesquisas no Brasil neste sentido é igualmente preocupante, porque revelam a inquietação: há atenção voltada as múltiplas pessoas expostas a violência intrafamiliar?

A relevância e importância em realizar uma pesquisa nesta temática é explicada através da necessidade de compreender a violência doméstica, enquanto fator que adoece vítimas diretas e indiretas. Adolescentes expostas a tais contextos compreendem os riscos e desenvolvem medos e receios a partir da referida realidade.

Ressaltamos que a presente pesquisa contou com um número limitado de participantes. É importante a continuidade de estudos e intervenções neste sentido, com o objetivo de alcançar um número maior de jovens que se sintam confortáveis em relembrarem experiências de violência que foram expostas/os. A partir de seus relatos, é possibilitada uma compreensão ainda mais ampla acerca da violência doméstica e de possíveis intervenções a ser realizadas com foco na referida temática.

Ao pensar em possíveis intervenções com adolescentes expostas a tais situações, percebe-se a possibilidade em desenvolver discussões sobre a violência no namoro com adolescentes (MURTA et al, 2015). Esta é uma vertente de intervenção bem-vinda, pois carrega o potencial de contribuir para a prevenção de violências e de promover a saúde mental entre jovens.

Há a urgente necessidade da atenção de pesquisas e atuações profissionais no âmbito das políticas públicas, voltarem-se à saúde das relações familiares, principalmente a partir de práticas de profissionais na área da saúde mental. É neste contexto que o desenvolvimento de ações de conscientização se faz importante. Estas carregam o potencial de promover a saúde, de detectar situações de risco na realização naturalizada de papeis sociais de gênero específicos para uma menina ou menino desempenharem na sociedade e prevenir o uso potencial de comportamentos agressivos nos relacionamentos, como manejo em resolução de conflitos. 


\title{
Adolescents perspectives about gender, relationship and violence
}

\begin{abstract}
The purpose of this research is to analyse in which ways female adolescents that witness violences against their mothers by those who represents the paternal figure, understands gender roles, relationships and violences in their daily lives. This research question mobilized our interest in doing the present study, on aiming to access those understandings at adolescence, through exposure on violent relationships that make up the adolescent's parents conjugal dynamic. The research is a cut of a master's thesis, elaborated through feminist theories, carried out with two female adolescents. The experiences of violence go beyond the (complex) functioning of family relationships. The adolescents constructs their ideas and concepts of "being a woman" and "being a man" at contemporary times, as well as concepts of relationship and violence, from conjugal relationships close to their lives.
\end{abstract}

KEYWORDS: Domestic violence. Adolescents. Mothers. Gender.

\section{Perspectivas de adolescentes sobre género, relaciones y violencias}

\author{
RESUMEN
}

El objetivo de este artículo es analizar de qué maneras adolescentes que presencian sus madres como víctimas de la violencia doméstica por aquellos que representan la figura paterna, comprenden los papeles de género, relaciones y violencias en su cotidiano. Para alcanzar este objetivo el presente estudio fue construido, al buscar acceder a tales comprensiones en el proceso de adolescencia, a partir de la exposición a las relaciones violentas que componen la dinámica conyugal de los padres de las adolescentes. Se trata de un recorte de una disertación de maestría, elaborada a través de las teorías feministas, realizada con dos adolescentes del género femenino. Se constató que las experiencias de violencia traspasan el (complejo) funcionamiento de las relaciones familiares. Las adolescentes construyen sus ideas y conceptos de "ser mujer" y "ser hombre" en la contemporaneidad, así como conceptos de relaciones amorosas y violencia, a partir de relaciones conyugales parentales cercanas a sus convivencias.

PALABRAS CLAVE: Violencia doméstica. Adolescentes. Madres. Género. 


\section{REFERÊNCIAS}

ACKERLY, Brooke; TRUE, Jaqui. Back to the future: feminist theory, activism, and doing feminist research in an age of globalization. Women's Studies International Forum, v. 33 n. 5, p. 464-472, 2010.

BANDEIRA, Lourdes Maria. Violência de gênero: a construção de um campo teórico e de investigação. Revista Sociedade e Estado,v. 29 n. 2, p. 449-469, 2014.

BANDEIRA, Lourdes; THURLER, Ana Liési. A vulnerabilidade da mulher à violência doméstica: aspectos históricos e sociológicos. In: LIMA, Fausto Rodrigues; SANTOS, Claudia (Org.), Violência Doméstica - vulnerabilidades e desafios na intervenção criminal multidisciplinar. Rio de Janeiro: Lumen Juris, 2010, p. 159-168.

BERNADINO, Jéssica Lorena Alves; SILVA, Edilene Oliveira. Representações da violência de gênero e raça no documentário Doméstica, de Gabriel Mascaro, 2012. In: STEVENS, Cristina; OLIVEIRA, Susane; ZANELLO, Valeska; SILVA, Edlene; PORTELA, Cristiane (Org.) Mulheres e violências: interseccionalidades. EBook, PDF. Brasília, DF: Technopolitik, 2017, p. 145-164.

BRASIL. Ministério da Saúde, Brasil, Secretaria de Políticas de Saúde. Violência intrafamiliar: orientações para prática em serviço. Brasília: Ministério da Saúde, 2001. Disponível em: < http://bvsms.saude.gov.br/bvs/publicacoes/cd05_19.pdf>. Acesso em: 05 de jan. 2018.

CARLOTO, Cássia Maria; MARIANO, Silvana. A família e o foco nas mulheres na política de assistência social. Sociedade em Debate, v. 14 n. 2, p. 153-168, 2008.

CHAUI, Marilena. Ética, violência e política. In: CHAUI, Marilena. Cultura e democracia: o discurso competente e outras falas. 13. Ed. - São Paulo: Cortez, 2011. p. 340-359.

EVANS, Sarah; DAVIES, Corrie; DILILLO, David. Exposure to domestic violence: A meta-analysis of child and adolescent outcomes. Aggression and Violent Behavior, v. 13, n. 2, p. 131-140, 2008.

DINIZ, Gláucia. Conjugalidade e Violência: reflexões sob uma ótica de gênero. In: FÉRES-CARNEIRO, Terezinha (Org.): Casal e família: conjugalidade, parentalidade e psicoterapia. São Paulo: Editora Casa do Psicólogo, 2011, p. 11-26.

DINIZ, Gláucia Ribeiro Starling; ANGELIM, Fábio. Pereira. Violência doméstica - Por que é tão difícil lidar com ela? Revista de Psicologia da UNESP, v. 2 n.1, p. 20-35, 2003.

DINIZ, Gláucia; FÉRES-CARNEIRO, Terezinha. Casamento e família: uma reflexão sobre desafios da conjugalidade contemporânea. In: VIANA, Terezinha de Camargo; DINIZ, Gláucia Starling; COSTA, Liana Fortunato; ZANELLO, Valeska (Org.), Psicologia Clínica e Cultura Contemporânea. Brasília: Liber Livros, 2012, p. 430-447. segredo nos contextos de violência doméstica. In: MALUCHKE, Günther; BUCHER- 
MALUCHKE, Júlia S.N.F.; HERMANNS, Klaus. Direitos humanos e violência: desafios da Ciência e Prática. Fortaleza: Fundação Konrad Adenauer, 2004, p. 171-185.

D’AFFONSECA, Sabrina Mazo; WILLIAMS, Lúcia Cavalcanti de Albuquerque. Habilidades Maternas de Mulheres Vítimas de Violência Doméstica: Uma Revisão da Literatura. Psicologia: Ciência e Profissão, v. 31 n. 2, p. 236-251, 2011. Disponível em: <http://www.scielo.br/pdf/pcp/v31n2/v31n2a04.pdf>. Acesso em: 05 jan. 2018.

JORDÃO, Aline Bedin. Vínculos familiares na adolescência: nuances e vicissitudes na clínica psicanalítica com adolescentes. Aletheia, v. 27 n.1, p. 157-172, 2008.

MURTA, Sheila Giardini; MIRANDA, Ana Aparecida Vilela; BEZERRA, Karinne Leissa Torres; VERAS, Lydia Galdino; SANTOS, Karine Brito dos; CANGUSSÚ, Eudes Diógenes Alves; MOORE, Rafael Alberto. Programa de prevenção à violência no namoro e promoção de empoderamento em adolescentes. In: MURTA, Sheila Giardini; BUCHER-MALUSCHKE, Júlía, J. S.N.F.; DINIZ, Gláucia Ribeiro Starling (Org.) Violência no namoro: estudos, prevenção e psicoterapia. Curitiba: Appris, 2015, p. 203-226.

NARVAZ, Martha Giudice; KOLLER, Sílvia Helena Famílias e patriarcado: da prescrição normativa à subversão criativa. Psicologia \& Sociedade, v.18 n.1, p. 4955, 2006.

PEIXOTO, Paula Carvalho Quando o gênero legitima a violência contra a mulher e a violência doméstica. In: BARBOSA, Theresa Karina Figueiredo Gaudêncio (Org.) A mulher e a justiça: a violência doméstica sob a ótica dos direitos humanos. Brasília: AMAGIS-DF, 2016, p. 111-124.

RESSEL, Lucia Beatriz, SEHNEM, Graciela Dutra, JUNGES, Carolina Frescura, HOFFMAN, Izabel Cristina; LANDERDAHL, Maria Celeste. Representações culturais de saúde, doença e vulnerabilidade sob a ótica de mulheres adolescentes. Escola Anna Nery Revista de Enfermagem, v.13 n.3, p. 552-557, 2009.

SAFFIOTI, Heleieth. Gênero Patriarcado Violência. 2. Ed., São Paulo: Expressão Popular, Fundação Perseu Abramo, 2015.

SANTOS, Ana Cláudia Wendt dos; MORÉ, Carmen Leontina Ojeda Ocampo. Impacto da violência no sistema familiar de mulheres vítimas de agressão. Psicologia: Ciência e Profissão, v. 31 n. 2, p. 220-235, 2011.

SILVA, Luciene Lemos; COELHO, Elza Berger Salema; CAPONI, Sandra Noemi Cucurullo de. Violência silenciosa: violência psicológica como condição da violência física doméstica. Interface - Comunicação, Saúde, Educação, v. 11 n. 21, p. 93103, 2007.2 Disponível em: <http://www.scielo.br/pdf/icse/v11n21/v11n21a09.pdf>. Acesso em: 20 de jan. de 2018.

WAISELFISZ, Júlio Jacobo. Mapa da Violência 2015: Homicídio de mulheres no

Brasil. Flacso, Brasília - DF, 2015. Disponível em: www.mapadaviolencia.org.br/pdf2015/MapaViolencia_2015_mulheres.pdf. 
Acesso em: 20 de jan. De 2018.

Recebido: 10/04/2019.

Aprovado: 20/06/2019.

DOI: $10.3895 /$ cgt.v12n40.9962

Como citar: ROCHA, Isadora Oliveira; DINIZ, Glaucia Ribeiro Starling. Perspectivas de adolescentes sobre gênero, relacionamentos e violências. Cad. Gên. Tecnol., Curitiba, v. 12, n. 40, p. 230-242, jul./dez., 2019. Disponível em: https://periodicos.utfpr.edu.br/cgt. Acesso em: XXX.

Correspondência:

Isadora Oliveira Rocha

Rua João Ferraz de Magalhães, n 432, Bairro Santa Helena II. Catalão, Goiás.

Direito autoral: Este artigo está licenciado sob os termos da Licença Creative Commons-Atribuição 4.0 Internacional.

(c) (i) 